\title{
From On-site to Online Class: The Role of Mediation in Online Teaching Simulation
}

\author{
Oksana Polyakova, Beatriz Pastor García \\ Universitat Politècnica de València
}

\begin{abstract}
Correspondence concerning this article should be addressed to Oksana Polyakova, Universitat Politècnica de València, Departamento de Lingüística Aplicada (edificio 4P), Camino de Vera, s/n, 46022 Valencia.

E-mail: okpolnes@upv.es
\end{abstract}

\begin{abstract}
This paper presents the findings of a pilot study that explored the relationship between mediation and teaching simulation activities during a postgraduate course for CLIL (Content and Language Integrated Learning). A controversial factor of the experiment was the overall lockdown that happened in Spain during the Spring through Summer of 2020. These extenuating circumstances compelled the lecturers to innovate by transforming a traditional on-site classroom practice into an online training opportunity. There were forty-two participants in the English language training for the content teacher's course. This pilot project was taught at the Catholic University of Valencia. The pilot study's outcomes were the display of feasibility of the curricular adaptation by providing (1) CLIL teaching simulation planning, (2) teaching simulation assessment sheet and (3) questionnaire responses, all of them closely related to mediation and online education. The analysis of the data collected through the study outcomes yielded positive effects of the methodology used. Therefore, the initial results suggest the possibility of this curricular update. We recommend developing the connection between mediation, online instruction and CLIL teacher training opportunities by applying the lessons learned in an authentic school setting.
\end{abstract}

Keywords: mediation, online teaching training, teacher training, CLIL, teaching simulation, Covid-19

\section{Introduction}

Since the beginning of civilisation, the concept of mediation has existed as a feasible solution to solve problems in many different fields. Additionally, life in a globalised world requires language mediation to reach agreements, understandings and sensitivities within our plurilingual and multicultural societies. The Common European Framework of Reference (CEFR) promotes cultural awareness and communication skills, placing emphasis on observing or enhancing our language capacity. The CEFR Companion 2018 version (Council of Europe, 2018) considers that mediation or mediating communication should facilitate understanding and accomplish a successful communication between speakers with different cultural, linguistic or intellectual backgrounds.

One cannot deny the importance of mediation as an integral part of Vygotsky's theory: its connection as an explanatory self-dialogue, teacher and peer mediation is expandible and adaptable to the technology-based mediation process (Guerrero Nieto, 2007). Moreover, the FL educator's role involves mediation for internationalisation (Räsänen, 2011) and the conceptual mediation of language between the student and the unknown curricular content (Ball et al., 2016). Precisely the last idea is so natural for CLIL or Content and Language Integrated Learning classrooms that we will advocate for the nexus of knowledge development via L2 and mediation throughout this study.

It should be noted that numerous experts highlight the didactic, methodological, instrumental and innovative role of CLIL ${ }^{1}$ (Coyle et al., 2010; Marsh, 2002). This method aims at achieving an equally relevant position of

\footnotetext{
${ }^{1}$ Eurydice (2006). Content and language integrated learning (CLIL) at school in Europe. Education Information Network in the European Union (Eurydice).
} 
both language and content training while teaching a curricular subject at school. Even though the CLIL approach has at times been questioned on the grounds of the specific value assigned to content and L2 (Cenoz et al., 2014) or certain linguistic or socio-political limitations related to the imperialistic role of certain foreign languages (Ravelo, 2014), we strongly support its use.

Consequently, the search for a reliable method to reinforce educational mediation, knowledge and foreign language at school successfully led to the Content and Language Integrated Learning approach. Additionally, several studies analysed CLIL implementation in different countries and detected its positive results on pupils` English as a Foreign Language (EFL) outcomes (Brevik \& Moe, 2012; Delliou \& Zafiri, 2016) or even selfconfidence to use foreign language (Simons et al., 2019). There is also a specific recognition on the part of teachers, for whom content training in English is beneficial for students`communicative and content skills. However, some educators expressed their concerns about limited subject knowledge of content areas (McDougald, 2015). Other drawbacks listed include students`low English level, absence of teaching materials, lack of institutional and companion support and not being competent enough in the subject matter (PladevallBallester, 2015).

In the 1990s, CLIL was promptly accepted by many European countries and first launched in Finland (Hanesová, 2015). Its adaptation brought the necessity to combine financial and institutional support and specific teacher training (Banegas, 2012; Nikula et al., 2016; Wolff, 2012). CLIL teachers' professional development's primary goal is to promote L2, CLIL methodological updates and boost their communicative and mediation competences. Such skills as reframing, summarising, relaying information, explaining data, collaborating to construct meaning or cooperation and interaction strategies are closely related to the CEFR Companion indications (Council of Europe, 2018). Each aspect of communicative preparation is essential for an educator-mediator and crucial for creating a specific CLIL teacher training course.

During this postgraduate programme, the development of communication and mediation are at the heart of training as both play an essential role in regulating interaction and knowledge transfer due to the Covid-19 pandemic. According to a recent study of such factors as satisfaction, functional performance and learning expectations (Özgen \& Reyhan, 2020), the sudden switch from an in-person to a long-distance learning education format, caused by pandemic restrictions, is not the only challenge facing university students. It is necessary to create a new learning culture that is tailored to online or mobile training platforms. Moreover, current pedagogical mediation challenges (Cerdas-Montano et al., 2020) may be the initial point of reference for creating communication and mediation essentials while teaching online. Having established these priorities, the researchers address the following questions:

(RQ1) What are the key issues affecting the development of CLIL teachers' communicative and mediation competences?

(RQ2) How can we adapt English for content instructors` course tasks to online training?

(RQ3) How can teachers adapt the CLIL didactic unit, lesson or activity to online teaching? How can mediation help address this?

The paper has been organised as follows. Primarily, we confirm the need for professional, communicative development for future CLIL educators-mediators. Secondly, we explain how the pilot study was carried out by comprising a list of materials and methods (participants and setting, training process outline, assessment and measurement instruments). In the end, we summarise and discuss the research findings necessary to form definitive conclusions.

\section{Literature Review}

\section{Mediation}

In the last decades, the complex process of L2 testing, learning and teaching has extended towards more communicative approaches. Hence, there is a change in the traditional terminology from the four skills to the four types of activity: reception, interaction, production and mediation (Lado, 1961). 
In this respect, the CEFR emphasises the importance of mediation and its social dimension «in both receptive and productive modes since the oral and written activities of mediation make communication possible between learners who are unable, for whatever reason, to communicate with each other directly» ${ }^{2}$ (p. 4). It means language is transformed into a tool to enhance communication and reciprocal comprehension (Swain, 2006; Wood et al., 1976). Language users consciously apply and adapt a wide range of strategies to better understand, including numerous activities varying from data collection and explanation to creating a positive multicultural space.

The recent trend to consider learners as social agents means recognising the «social nature of language and language use, the interaction between the social and the individual in the process of learning» (Council of Europe, 2018, p. 27). Also, CLIL's approach implies that purposeful and collaborative tasks in the classroom should focus on a meaningful outcome.

Within our online training scenarios, there are several features that differ from on-site interaction. In our research, we have considered the following ones:

- $\quad$ in a face-to-face situation, speaking interaction provides immediate feedback or reaction. Although it is possible that countless resources can be shared in the online interaction, it is also true that not all learners have access to a camera, microphone, or the necessary Wi-Fi connection to engage in a simple conversation.

- $\quad$ another aspect related to online sessions is the loneliness of learners who usually work individually in an environment that might involve external distractions or disruptions. Due to these circumstances, we consider mediation necessary to meet effective communication and education targets.

\section{CLIL teacher training}

Education in the $21^{\text {st }}$ century is not about performing well on academic tests at school but instead about completing the significant commitments on key transformative competences such as creating new values or innovating, reconciling tensions or interconnecting and taking responsibility or evaluating personal actions ${ }^{3}$ (Raitskaya \& Tikhonova, 2019). In line with this, effective and quality acquisition of an additional or foreign language may be accomplished through various language exposure opportunities, Content and Language Integrated Learning being such a meaningful education spotlight (Marsh et al., 2020).

Purposely applied to the field of CLIL teacher training, the definition of CLIL suggested by Marsh et al. ${ }^{4}$ (2011, p. 1) denominates it as «a dual-focused educational approach in which an additional language is used for the learning and teaching of content and language to promote both content and language mastery to pre-defined levels». The designation is clear as for most parts of CLIL: it highlights the dual nature of the methodology where both parts, subject and L2, are to be advanced, relying upon pre-characterised abilities in two school subjects, the language and the specific subject (Wolff, 2012).

Many content subject teachers (usually not EFL teachers) are responsible for content educational tasks in L2 in Spanish state-run and private state-funded schools. The only requirement to access this position is to provide an official certificate of a foreign language's B2/C1 level. Nevertheless, as McDougald (2015) and PladevallBallester (2015) pointed out above, content teachers observe the language level might not be the unique factor in meeting academic goals. The CEFR moves beyond the traditional language skills, opening to a more complex vision that includes mediation and interaction to offer complete language learning and language use integration (Piccardo et al., 2019).

\footnotetext{
2 North, B., \& Piccardo, E. (2016). Developing illustrative descriptors of aspects of mediation for the CEFR. Strasbourg, France: Council of Europe. Rm. Coe. Int/Common-European-Framework-of-Reference-for-Languages-Learning-Teaching/168073ff31.

3 OECD. (2019). Future of Education and Skills 2030 Conceptual learning framework: Transformative competences for 2030. https://www.oecd.org/ education/2030-project/teaching-and-learning/learning/transformative-competencies/Transformative Competencies for 2030 concept note.pdf

4 Marsh, D., Mehisto, P., Wolff, D., \& Frigols Martín, M. J. (2011). European Framework for CLIL Teacher Education. A Framework for the Professional Development of CLIL Teachers. European Centre for Modern Languages. https://ebuah.uah.es/dspace/bitstream/handle/10017/14881/CLIL-Framework_Marsh.pdf?sequence=1
} 
Our proposal, detailed in this pilot study, deals with the use of mediation activities in the development of an online teaching simulation, based on CLIL principles to communicate effectively, remarking how «the competence of the communication is at the heart» of teaching and learning (Vyushkina, 2018, p. 216).

The goal of this pilot study is to verify the feasibility of a curriculum activity adaptation empirically. Widely used in health research and social studies (Kim, 2011; Lancaster et al., 2004), pilot studies' importance as small-scale testing provides valuable insights into monitoring, applying, and improving new education practices (Baker-Henningham et al., 2009). A pilot study-based development of new methodologies represents a unique opportunity to enhance pre-established curriculum design and adjust some of its activities to the new situation of Covid-19 training.

\section{Methodology}

\section{Participants and Setting}

A pilot study was conducted at the Catholic University of Valencia facilities and through an online platform from February 2020 to May 2020. A total of 42 in-service and pre-service teachers enrolled in the English language for content instructors training course based on CLIL methodology (24 ECTS, postgraduate qualification) agreed to participate in the research. Two university lecturers in charge of teaching two groups (26 and 16 participants) ran the programme and simultaneously performed the research. A permanent collaboration of these university research and teaching staff members in other academic projects or innovative initiatives helped better understand the project aims, protocol, and approach.

\section{Training Process Outline}

The English language course for content instructors is a specific course to prepare schoolteachers for imparting a subject in an additional foreign language. Two types of skills are being trained: the expert competency of the effective CLIL method use and the linguistic capacity of classroom application at the B2 level of English, as per the CEFR. The on-site course structure comprises three separate but interrelated modules. These parts include Module 1-Methodology, Module 2-Assessment and Module 3-Materials and resources for plurilingual education. All course materials, calendars and assessment systems were accessible on the Moodle platform and were used throughout the training process of 18 weeks.

The course was intended to be finished without any mode switch. In contrast, due to the event of a major obstacle, Covid-19 lockdown in Spain, our institution had to split it up into two modalities: on-campus (February 3 - March 18) and online (March 23 - May 18). Details of the on-site and online training course framework can be found below:

- phase 1, interactive lecturing combining presentations and seminars narrated in English offered userfriendly input information on the theoretical and practical method foundations.

- $\quad$ phase 2, teaching skills development and practical hands-on activities to apply the information previously taught.

It is worth mentioning the fact that the initial course planning established mainly face-to-face assignment deliveries such as individual didactic unit structure presentation, materials and resources design for the same unit, collaborative presentations on selected theoretical topics or teaching simulation activities.

In the course framework, special attention is paid to an in-class teaching simulation. This activity's primary goal is to guide a small group of three or four CLIL teachers-in-training from different content backgrounds towards a progressive creation of a cooperative lesson plan. Instead of using a computer simulation programme, we encourage educators to carry out practical activities, implement real-life classroom management techniques and imitate a real-life training situation by teaching colleagues from other groups. This genuine scenario makes students explore L2 and content interaction, encouraging a wholesome reflection on our trainees' professional development. 


\section{Methods}

The following figure provides an overview of the sequencing and methodology used.

\section{Figure 1}

\section{Pilot Study Chart}

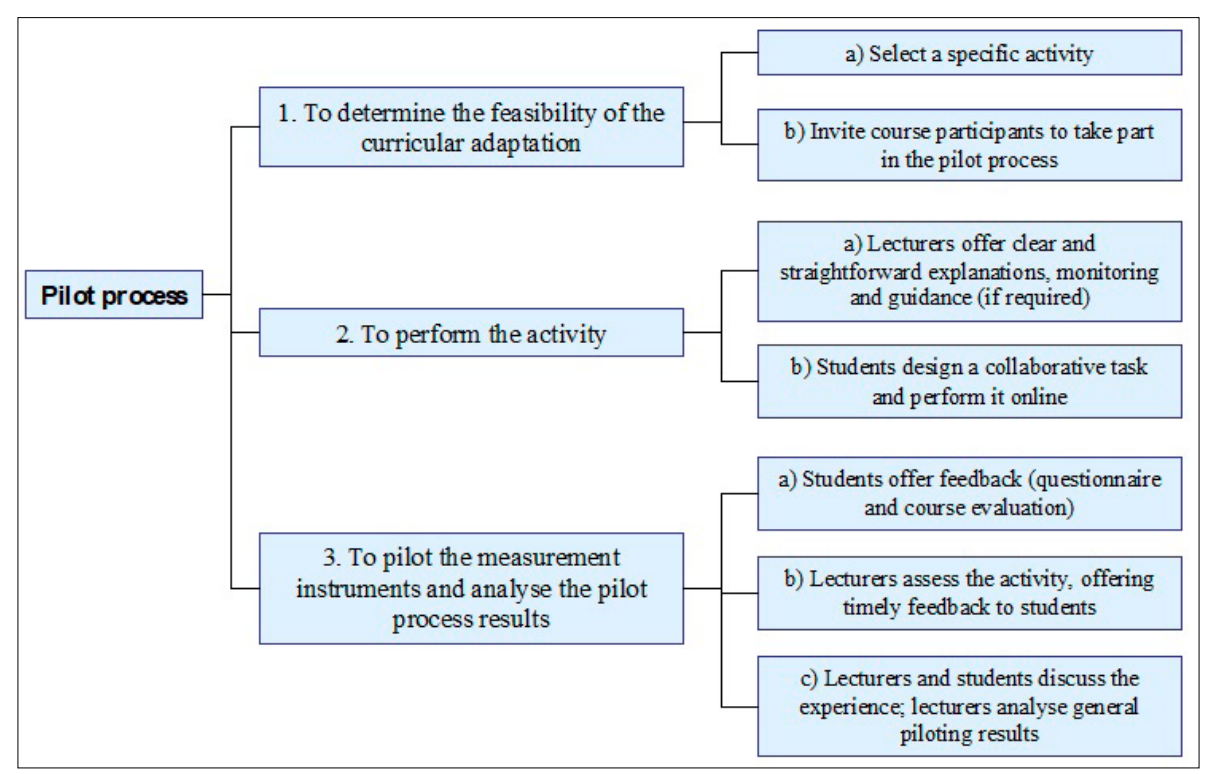

As illustrated in Figure 1, we motivate our qualitative study method for tackling the research questions listed in the introductory section. The process's design consists of three interconnected components: investigation purpose, activity implementation, and outcomes` estimations. For this research, (1) we first detected the necessity to adapt the training curriculum and then chose teaching simulation to perform during the course participants' investigation. Throughout the training, (2) future CLIL students participated in a collaborative lesson design and demonstration adjusted to an online environment. Finally, (3) to assess study results, the trainees responded to a questionnaire, discussed their experience and both lecturers reviewed the overall pilot study results.

\section{Assessment and Measurement Instruments}

For the teaching simulation assessment, we considered it appropriate to have student participation. There is no doubt that peer assessment promotes students` involvement and implication, giving them the chance to reflect on performance quality. Accordingly, participants prepared their rubric, applying it to their teaching simulation lesson. Each group had to think about three points to assess, varying from materials and resources to mediation. Once the lesson had been designed, the group chose the most significant aspects for the rubric, created the assessment sheet and shared it with their colleagues before starting their online teaching simulation. Thus, while bearing in mind this rubric, course participants from other groups could fill in the assessment document during the activity. The lecturer collected evaluation data and encouraged learners to congratulate the best online teaching simulation creators on keeping the assessment process.

Also, a questionnaire was designed to observe how the pandemic situation had affected the course design. For example, the respondents commented on suggestions to develop communicative competences, mediation, plurilingual and pluricultural competences for teaching in English in our current situation or the main challenges your students might face in the case of offering online training at school in the future (communication difficulties, technological challenges, motivation or learning issues among others). 


\section{Results}

The implementation of the pilot study provides empirical findings that might be described in line with the subsequent subdivision: (1) an example of a teaching simulation lesson supported by the mediation focus; (2) an example of an assessment rubric to evaluate the teaching simulation proposed; (3) a questionnaire focused on the teaching simulation and a group discussion evaluating experimental study outcomes.

\section{Outcome 1. Teaching Simulation}

Motivated by the need for content and language integration, we now introduce an example of a CLIL teaching simulation task elaborated by a group of course trainees. The online cross-curricular lesson design's main emphasis was on knowledge, L2 and mediation via clear and straightforward planning. Table 1 below shows a sequence of stages varying from introduction to a questionnaire where the mediation of texts and concepts occurred.

The lesson plan presented the topic for an online teaching scenario and was executed during the English language for content instructors' course (UCV Moodle platform, Blackboard Collaborate tool). To underpin collective mediation activities, we created a particular option for small group work.

The teaching simulation was performed in the following way. Lesson authors divided the structure into four parts; each part was created and taught by its author. Such a realistic setting helped future content instructors deal with every aspect of online CLIL teaching and mediation.

\section{Outcome 2. Teaching Simulation Rubric}

This study phase generally accompanies the execution process providing information on the teaching simulation effectiveness as perceived by learners. The Healthy eating teaching simulation authors designated the specific lesson aspects (materials, content, language, performance, assessment, feedback and mediation) for being measured by other participants, as illustrated in Table 2. After each teaching simulation activity, this assessment sheet was handed out to participants to ask their opinion about the training. As we have already explained, the students had previously prepared the rubric and it was branded as a questionnaire to maintain data privacy.

\section{Table 1}

\section{Teaching Simulation Planning}

Topic: Healthy eating

Cross-curricular online lesson plan for secondary school pupils

Authors: four secondary school / vocational training teachers (cooking, occupational training, computing, marketing \& economy teachers)

[All materials and resources presented below were carefully designed, produced and organised by the group members under the supervision of the course lecturer]

\begin{tabular}{|c|c|}
\hline Activities planned & $\begin{array}{l}\text { Mediation done by learners [according to the categories established } \\
\text { by CEFR } 2018 \text { \& Piccardo et al. (2019)] }\end{array}$ \\
\hline $\begin{array}{l}\text { 0. Introduction } \\
\text { A short video presenting the lesson plan: food vocabulary, food } \\
\text { groups, frequency of consumption of each type of food }\end{array}$ & Mediating a text: processing a text in speech \\
\hline $\begin{array}{l}\text { 1. Vocabulary } \\
\text { 1.1. Video presentation of the lesson vocabulary ( } 6 \text { mins): } \\
\text { images, written word, pronunciation }\end{array}$ & $\begin{array}{l}\text { Mediating a text: processing a text in speech \& visuals; translating; } \\
\text { note-taking }\end{array}$ \\
\hline $\begin{array}{l}\text { 1.2. Short visual vocabulary presentation (visual presentation, } 9 \\
\text { slides on Genial.ly): } \\
\text { food groups }\end{array}$ & $\begin{array}{l}\text { Mediating a text: processing a text in speech \& visuals; translating; } \\
\text { note-taking }\end{array}$ \\
\hline $\begin{array}{l}\text { 1.3. It's time to play } \\
\text { Vocabulary game } 1 \text {, general food vocabulary (leariningapp.org) } \\
\text { Memory card game for reviewing vocabulary taught }\end{array}$ & $\begin{array}{l}\text { Mediating concepts: collaborating in small groups; managing } \\
\text { interaction; collaboration to construct meaning }\end{array}$ \\
\hline
\end{tabular}




\section{OKSANA POLYAKOVA, BEATRIZ PASTOR GARCÍA}

2. Activate

2.1. Short video reminding food groups and introducing Mediating a text: processing a text in speech \& visuals nutrition value of different types of food

\subsection{3,2,1, start!}

Vocabulary game 2, food groups (leariningapp.org)

Extra: a short video presenting and explaining correct answers

3. Practice

3.0. Short video presentation, general information about the food pyramid

3.1 Create your food pyramid (a pyramid template available)

3.2. What is in the NAOS (Strategy for Nutrition, Physical Activity and the Prevention of Obesity) pyramid?

Online matching game: different types of food and various types of consumption (daily, weekly and occasional)

\subsection{More information about NAOS pyramid - recommended Mediating a text: processing a text in speech \& visuals} food consumption (6 slides, Genial.ly)

\subsection{Writing task}

Compare the Naos Pyramid with the pyramid that you have created in the previous exercise and write your conclusions (75 words, a template is available)

4. Check

4.1. Final quiz (Kahoot game)

Extra: a short video presenting and explaining correct answers

\section{Questionnaire}

Healthy food lesson questionnaire (Google Forms, 6 questions

about the lesson structure, content, design and organisation, technical issues, timing and usefulness of the activities).

\section{Table 2}

\section{Teaching Simulation Assessment Sheet}

\begin{tabular}{|c|c|c|c|c|c|}
\hline MATERIAL & 1 & 2 & 3 & 4 & 5 \\
\hline Are the materials used appropriately to the age of the student? & & & & $\mathrm{X}$ & $\mathrm{X}$ \\
\hline Are the materials suitable for students' interests and needs? & & & & $\mathrm{X}$ & $\mathrm{X}$ \\
\hline Are the materials stimulating for learning? & & & & $\mathrm{X}$ & $\mathrm{X}$ \\
\hline CONTENT & 1 & 2 & 3 & 4 & 5 \\
\hline Is there any specific content for children with specific needs? & & & & $\mathrm{X}$ & \\
\hline Is the content meaningful for their daily life? & & & & $\mathrm{X}$ & $\mathrm{X}$ \\
\hline Is there a clear structure for the content? & & & & $\mathrm{X}$ & $\mathrm{X}$ \\
\hline LANGUAGE ACTIVITIES & 1 & 2 & 3 & 4 & 5 \\
\hline Do the activities allow interaction? & & & & & $\mathrm{X}$ \\
\hline Is the language used appropriately for the level of the student? & & & & & $\mathrm{X}$ \\
\hline Has fluency been worked on? & & & & & $\mathrm{X}$ \\
\hline $\begin{array}{l}\text { Do the students spontaneously use the second language for } \\
\text { learning? }\end{array}$ & & & & $\mathrm{X}$ & \\
\hline PERFORMANCE & 1 & 2 & 3 & 4 & 5 \\
\hline Is it a dynamic performance? & & & & & $\mathrm{X}$ \\
\hline Is it a performance with a coherent structure? & & & & $\mathrm{X}$ & $\mathrm{X}$ \\
\hline Has it been inclusive for all the students? & & & & $\mathrm{X}$ & \\
\hline
\end{tabular}

Mediating concepts: collaborating in small groups; managing

interaction; collaboration to construct meaning.

Mediating a text: processing a text in speech \& visuals

Mediating a text: processing a text in speech \& visuals; translating;

note-taking

Mediating a text: expressing a personal response to a creative task

Mediating concepts: collaborating in small groups; managing

Mediating concepts: collaborating in small groups; managing interaction; collaboration to construct meaning.

Mediating a text: processing a text in writing

Mediating a text: processing a text in speech \& visuals; translating interaction; collaboration to construct meaning

Mediating a text: processing a text in writing 


\begin{tabular}{|c|c|c|c|c|c|}
\hline ASSESSMENT & 1 & 2 & 3 & 4 & 5 \\
\hline Is the assessment adapted to the content? & & & $\mathrm{X}$ & & \\
\hline Is the student an active agent in his/her assessment? & & $\mathrm{X}$ & & & \\
\hline Have the activities been appropriate for the students? & & & & & $\mathrm{X}$ \\
\hline Could another teacher carry out the class? & & & & & $\mathrm{X}$ \\
\hline FEEDBACK & 1 & 2 & 3 & 4 & 5 \\
\hline Has the teacher allowed the students to express feedback? & & $\mathrm{X}$ & & & \\
\hline Has the feedback been constructive? & & $\mathrm{X}$ & & & \\
\hline Have the teacher's corrections helped the student's reflection? & & & $\mathrm{X}$ & & \\
\hline MEDIATION & 1 & 2 & 3 & 4 & 5 \\
\hline Is there a specific mediation activity? & & & & & $\mathrm{X}$ \\
\hline Are there any oral mediation activities? & & & & & $\mathrm{X}$ \\
\hline Are there any written mediation tasks? & & & & $\mathrm{X}$ & \\
\hline
\end{tabular}

\section{Outcome 3. Questionnaire}

The evaluation of the teaching simulation experience related to the mediation and online training was conducted by questionnaire. According to the data available, 35 respondents to the poll expressed their opinions by answering the following three open-ended questions:

1. What are the main challenges you and your students might face in the case of offering online training and mediation? The participants consider that the most critical challenges are associated with «lack of knowledge» or «lack of attention». The solutions involve good access to new technology, training courses and mediation activities due to the lack of necessary or optimum teaching conditions.

2. Can you suggest an example of a task or activity designed for your lesson plans that you might adapt to the online CLIL teaching and mediation? All learners could offer an example requested (mediation of texts or concepts embedded in various content and language tasks).

3. Suggestions to develop communicative competences, mediation, plurilingual and pluricultural competences for teaching in English in the current pandemics' situation.

Responses to this question included videos, games or other educational material available online.

\section{Discussion}

In designing our pilot study, we strongly relied on existing work from several distinct areas. The concept and importance of mediation in second language acquisition, content learning and teacher training have been visualised before in the literature (Council of Europe, 2018; North \& Piccardo²; Vyushkina, 2018, among others). Continuing with this rationale, we developed a curricular adaptation for combining a CLIL postgraduate course with special instruction on mediation. Instead of addressing mediation from the mentoring point of view (Orland-Barak, 2014) or assessing the mediation role of L2 teachers (Azadi et al., 2018), we fostered it through the training of trainers. Finally, the online teaching simulation process was the practical choice for the overall lockdown situation in Spain.

To our knowledge, this research represents the first attempt to implement mediation within a curricular setting and raise awareness of its further applied use in content and language teacher training. Fulfilling this complex type of postgraduate instruction during the overall lockdown in Spain compelled lecturers to transform a traditional on-site classroom practice into an online training opportunity. Furthermore, the pilot study has demonstrated the feasibility of the curricular adaptation proposed. In the current experiment, 42 future content and L2 teachers took an active part in a new activity - an online teaching simulation with a particular focus on mediation. However, further research is needed to employ this approach in other cultural, educational and technological settings. 
Our pilot data verified the viability of the initial design of the experiment, consisting of three major points: to determine the feasibility of the curricular adaptation (1), to perform the collaborative lesson planning activity (2) and to pilot the measurement instruments and analyse the pilot process results (3). We are dealing with a creative training process on the university level and that makes us present empirical evidence, including the lesson plan, rubric and questionnaire.

The stages of this pilot study exhibit the techniques and proceedings of an exploration venture. While higher education course design contemplates utilising various plans, we include pilot testing of a specific training activity where general education principles, specific learning and assessment tools and overall quality standards apply. Thus, this experience can contribute to teacher training and content and L2 education, reinforcing the pedagogical value of mediation and online professional training.

\section{Conclusion}

The choice to direct a pilot study before introducing a significant curricular design modification might be a troublesome one for lecturers, course coordinators and academic directors. The current Covid-19 situation offered a unique opportunity of piloting new training approaches supported by the capacity-building framework, communicative competence development and mediation. Hence, at this stage, it appears that our pilot study has helped to address the initial research questions whose conclusions are summarised in the following manner:

(RQ1) Regarding the major challenges influencing CLIL educators' communicative and mediation competences, we observe mainly technical or methodological constraints at the beginning of the training process. Theoretical and practical preparation enables learners to overcome these difficulties, although we also reckon the on-site educational programmes might be more flexible for the online process.

(RQ2) One way of adapting course tasks to online training is a progressive modification of the assignments: from on-site to online. In general, learners remarked very positive opinions on the effectiveness of this process. Thus, we recommend involving the students in the process.

(RQ3) Adapting on-site to online teaching is a challenge that should often involve mediated communicative activities to enhance reciprocal comprehension.

Based on our information, this study is the first encounter with the theme of Covid-19 curricular adaptation from on-site to online teaching with new patterns to meet quality teacher preparation and mediation. Our study has allowed us to implement an activity that, although had been thought to be on-site, had to be carried out online and prove its feasibility successfully, according to the results obtained from the assessment sheet and feedback.

The analysis of the responses obtained shows how the project has achieved its goals of fostering mediated competence to replace the on-site sessions. Regarding the qualitative data obtained from the questionnaire and rubric, it is clear that the participants generated positive feedback. The most significant achievements we would like to highlight are the involvement of all the participants in their teamwork and linguistic enhancement. The Moodle platform and BlackBoard Collaborate use let them create several groups to work independently inside the session. Furthermore, the learners were able to prepare their teaching simulations with the help of Google classroom, which encouraged them to share different learning tips.

Despite certain study limitations (a small number of participants, a necessity to design more detailed questionnaires), we recommend developing a practical guide for CLIL mediation instruction and using online teaching simulation in further training options. The lessons learned in this pilot study can be applied for creating content and language practice workshops, including continuous professional development programmes. 


\section{Declaration of Competing Interest}

None declared.

\section{References}

Azadi, G., Biria, R., \& Nasri, M. (2018). Operationalising the concept of mediation in L2 teacher education. Journal of Language Teaching and Research, 9(1), 132-140. http://dx.doi.org/10.17507/jltr.0901.17

Banegas, D. L. (2012). CLIL teacher development: Challenges and experiences. Latin American Journal of Content \& Language Integrated Learning, 5(1), 46-56. https://doi.org/10.5294/laclil.2012.5.1.4

Baker-Henningham, H., Walker, S., Powell, C., \& Gardner, J. M. (2009). A pilot study of the Incredible Years Teacher Training programme and a curriculum unit on social and emotional skills in community preschools in Jamaica. Child: Care, Health and Development, 35(5), 624-631. https://doi.org/10.1111/j.13652214.2009.00964.x

Ball, P., Kelly, K., \& Clegg, J. (2016). Putting CLIL into practice: Oxford handbooks for language teachers. Oxford University Press.

Brevik, M. \& Moe, E.(2012).Effects of CLIL teaching onlanguageoutcomes. In D. Tsagari, \& I. Csépes (Eds.), Collaboration in language testing and assessment (pp. 213-227). Peter Lang.

Cenoz, J., Genesee, F., \& Gorter, D. (2014). Critical analysis of CLIL: Taking stock and looking forward. Applied Linguistics, 35(3), 243-262. https://doi.org/10.1093/applin/amt011

Cerdas-Montano, V., Mora-Espinoza, Á., Salas-Soto, S. E. (2020). Remote education in the university context: Necessary collaborative work for teaching pedagogical mediation in the time of Covid. Revista Electrónica Educare, 24, 33-36. https://doi.org/10.15359/ree.24-s.9

Council of Europe. (2018). Common European framework of reference for languages: Learning, teaching, assessment. Companion volume with new descriptors. Education Policy Division.

Coyle, D., Hood, P., \& Marsh, D. (2010). CLIL: Content and Language Integrated Learning. Cambridge University Press.

Delliou, A.\& Zafiri, M. (2016). Developing the speaking skills of students through CLIL: A case of sixth grade primary school students in Greece. The 5th Electronic International Interdisciplinary Conference. https://www. researchgate.net/publication/308194120

Guerrero Nieto, C. H. (2007). Applications of Vygotskyan concept of mediation in SLA. Colombian Applied Linguistics Journal, 9, 213-228. https://doi.org/10.14483/22487085.3152

Hanesová, D. (2015). History of CLIL. In Silvia Pokrivčáková (ed.) CLIL in Foreign Language Education: E-textbook for foreign language teachers (pp. 7-16). Constantine the Philosopher University. https://blog.ufes.br/ kyriafinardi/files/2017/10/History-of-CLIL-2015.pdf

Kim, Y. (2011). The pilot study in qualitative inquiry: Identifying issues and learning lessons for culturally competent research. Qualitative Social Work, 10(2), 190-206. https://doi.org/10.1177/1473325010362001T

Lado, R. (1961). Language testing: The construction and use of foreign language tests. Longman.

Lancaster, G. A., Dodd, S., \& Williamson, P. R. (2004). Design and analysis of pilot studies: Recommendations for good practice. Journal of Evaluation in Clinical Practice, 10(2), 307-312. https://doi.org/10.1111/j..2002.384. doc.X

Marsh, D. (2002). CLIL/EMILE-The European dimension: Actions, trends and foresight potential. University of Jyväskylä.

Marsh, D., Díaz-Pérez, W., Frigols Martín, M. J., Langé, G., Pavón Vázquez, V., \& Trindade, C. (2020). The bilingual advantage: The impact of language learning on mind \& brain. EduCluster Finland. https://www.languages.dk/ docs/Bilingual_Advantage_Position_Paper_Finland_2020.pdf

McDougald, J. (2015). Teachers' attitudes, perceptions and experiences in CLIL: A look at content and language. Colombian Applied Linguistics Journal, 17(1), 25-41. https://doi.org/10.14483/udistrital.jour.calj.2015.1.a02

Nikula, T., Dafouz, E., Moore, P., \& Smit, U. (2016). Conceptualising integration in CLIL and multilingual education. Multilingual Matters.

Orland-Barak, L. (2014). Mediation in mentoring: A synthesis of studies in teaching and teacher education. Teaching and Teacher Education, 44, 180-188. https://doi.org/10.1016/j.tate.2014.07.011

Özgen, C., \& Reyhan, S. (2020). Satisfaction, utilitarian performance and learning expectations in compulsory distance education: A test of mediation effect. Educational Research and Reviews, 15(6), 290-297. http:// dx.doi.org/10.5897/ERR2020.3995 
Piccardo,E., North, B., Goodier, T.(2019). Broadening the Ssope of language education:Mediation, plurilingualism, and collaborative learning: The CEFR companion volume. Journal of e-Learning and Knowledge Society, 15(1), 17-36. https://doi.org/10.20368/1971-8829/1612

Pladevall-Ballester, E. (2015). Exploring primary school CLIL perceptions in Catalonia: Students', teachers' and parents' opinions and expectations. International Journal of Bilingual Education and Bilingualism, 18(1), 4559. https://doi.org/10.1080/13670050.2013.874972

Raitskaya, L., \& Tikhonova, E. (2019). Skills and competencies in higher education and beyond. Journal of Language and Education, 5(4), 4-8. https://doi.org/10.17323/jle.2019.10186

Räsänen, A. (2011). The promise and challenge of CLIL (Content and Language Integrated Learning) as a mediator for internationalisation [Conference Presentation ]. The European Council/Polish Ministry of National Education Conference on «Multilingual Competences for Professional and Social Success in Europe», Warsaw.

Ravelo, L. C. (2014). Demystifying some possible limitations of CLIL (content and language integrated learning) in the EFL classroom. Latin American Journal of Content \& Language Integrated Learning, 7(2), 71-82. https:// doi.org/10.5294/4105

Simons, M., Vanhees, C., Smits, T., \& Van De Putte, K. (2019). Remedying Foreign Language Anxiety through CLIL? A mixed-methods study with pupils, teachers and parents. Revista de Lingüística y Lenguas Aplicadas, 14, 153-172. https://doi.org/10.4995/rlyla.2019.10527

Swain, M. (2006). Languaging, agency and collaboration in advanced language proficiency. In Heidi Byrnes (Ed.), Advanced language learning: The contribution of Halliday and Vygotsky. Continuum.

Vyushkina, E. (2018). Mediation: Framing a clil Course. Studies in Logic, Grammar and Rhetoric, 53(1), 213-222. https://doi.org/10.2478/slgr-2018-0012

Wolff, D. (2012). The European framework for CLIL teacher education. Synergies Italie, 8, 105-116.

Wood, D., Bruner, J. S., \& Ross, G. (1976). The role of tutoring in problem solving. Journal of Child Psychology and Psychiatry, and Allied Disciplines, 17(2), 89-100. https://doi.org/10.1111/j.1469-7610.1976.tb00381.x 